\title{
Brief Communication: On the Optimum Number of Metacarpals for Roentgenogrammetric Measurement
}

\author{
STANLEY M. GARN, TIMOTHY V. SULLIVAN, SALLY A. DECKER, \\ ANU VICTOR M. HAWTHORNE \\ Center for Human Growth and Development (S.M.G., T.V.S.), Nutrition \\ Unit, School of Public Health (S.M.G.), and Department of Epidemiology \\ School of Public Health (V.M.H.), University of Michigan, Ann Arbor, MI \\ 48109; College of Nursing, Saginaw Valley State College, University \\ Center, MI 48710 (S.A.D.)
}

The roentgenogrammetric approach to the measurement of bone mass and the relative amount of cortical bone began with a single bone (Metacarpal II), on one body segment (the hand) and on one side of the body (usually the left side). The early investigators selected the hand for study because posteroanterior (PA) hand radiographs involved very low radiation doses and with little scatter to the gonads. Besides, the hand could be positioned with great reliability, assuming the postero-anterior position. The second metacarpal, in turn, was selected because of its size and morphological stability. Concentration on one hand and one side of the body proved practical and cost effective in national and international surveys allowing the use of smaller cassettes or integral monopacks and low powered portable radiographic units (Garn, 1970; Garn et al., 1976).

After the general course of changes in cortical area and relative or percent cortical area became evident, investigators began to give attention to multiple metacarpals (IIIV) and both hands instead of just one (cf. Kusec et al., 1988; Van Hemert et al., 1990). It seemed reasonable to assume that more metacarpals might provide more information on bone quality than just one metacarpal alone, given shape variations and inherent mensurational errors. It was also logical to include both hands in radiographic surveys, theoretically doubling the amount of information without increasing the gonadal radiation dosage.

Though multiple metacarpals have been so measured, often on both hands (e.g., Horsman, 1976), it is still not clear whether the increased amount of radiogrammetric information is worth the additional mensurational time and effort. It is not known, for example, whether more metacarpals improve bone-size/body-size correlations or re- lationships to the fat-free mass, or whether more metacarpals improve long-term replicabilities or continuities, especially during the bone-losing period which begins in the fifth decade. This study was undertaken to address these questions.

This study is based upon 752 serial postero-anterior hand radiographs of 376 adult women followed for a period of $21.4 \pm 0.9$ years. All of the subjects were regular participants in the Tecumseh, Michigan, Community Health Survey, a total-population sampling with over $90 \%$ compliance (Napier et al., 1972; Garn et al., 1989). Thirty additional sets of radiographs were excluded for various technical reasons: insufficient density, improper positioning, or imperfect superimposibility. Measurements were made with dial-reading Helios INOX.YO needlepoint calipers, read-out to the nearest 0.1 mm (Garn, 1963; Garn, 1970; Garn et al., 1991) after superimposition of the earlier and later radiographs of each pair to identify a common midshaft site. The raw measurements included total subperiosteal diameter (T) and medullary width (M). The raw radiogrammetric measurements $\mathrm{T}$ and $\mathrm{M}$ were then computer-converted into 3 commonly used bone areas-total area (TA), medullary area (MA), and cortical area (CA) and one ratio (PCA). The sets of bone area values or ratios were then subjected to 2 kinds of comparisons, the first being long-term (21.4 year) intraindividual comparisons and the second being comparisons with body size and body composition.

All such comparisons were made, separately, for differing numbers and combinations of metacarpals, starting with metacarpal II (left) alone, and concluding with metacarpals II through IV on both sides. The

\footnotetext{
Received July 10, 1990; accepted January 18, 1991
} 
TABLE 1. 21.4 year replicabilities for bone areas using different combinations of metacarpals ${ }^{1}$

\begin{tabular}{|c|c|c|c|c|c|c|c|}
\hline \multirow[b]{2}{*}{ Metacarpals } & \multirow[b]{2}{*}{$\begin{array}{l}\text { No. } \\
\text { Bone }\end{array}$} & \multirow[b]{2}{*}{$\begin{array}{l}\text { Entry } \\
\text { age }\end{array}$} & \multirow[b]{2}{*}{$\mathrm{N}$} & \multicolumn{4}{|c|}{ Long-term replicabilities for } \\
\hline & & & & $\begin{array}{l}\text { Total } \\
\text { area }\end{array}$ & $\begin{array}{c}\text { Medullary } \\
\text { area }\end{array}$ & $\begin{array}{c}\text { Cortical } \\
\text { area }\end{array}$ & $\begin{array}{c}\text { Percent } \\
\text { cortical area }\end{array}$ \\
\hline II Left & 1 & $30-39$ & 239 & 0.904 & 0.750 & 0.799 & 0.669 \\
\hline II Left & 1 & $40-49$ & 137 & 0.928 & 0.657 & 0.848 & 0.556 \\
\hline II $\mathrm{L}+\mathrm{R}$ & 2 & $30-39$ & 239 & 0.916 & 0.777 & 0.804 & 0.675 \\
\hline $\mathrm{II} \mathrm{I}+\mathrm{R}$ & 2 & $40-49$ & 137 & 0.949 & 0.676 & 0.823 & 0.518 \\
\hline II-III L + R & 4 & $30-39$ & 238 & 0.943 & 0.778 & 0.812 & 0.691 \\
\hline II-III L $+\mathrm{R}$ & 4 & $40-49$ & 136 & 0.959 & 0.699 & 0.823 & 0.574 \\
\hline II-IV L $+R$ & 6 & $30-39$ & 235 & 0.839 & 0.653 & 0.832 & 0.727 \\
\hline II-IV L + R & 6 & $40-49$ & 136 & 0.798 & 0.609 & 0.847 & 0.604 \\
\hline
\end{tabular}

"All values of $r$ significant at $P=0.001$ or better.

number of metacarpals thus investigated and reported here was 1 (II L), 2 (II L and R), 4 (II-III $L$ and R) and 6 (II-III-IV, L and R).

Separate analyses were also made for different numbers and combinations of metacarpals with the summed values for all 6 metacarpals, left and right. In this way we were able to compare the contributions of different pairings of metacarpals (e.g., II L and $R$ vs. II and III $L$ ) to the summed or averaged bone areas and ratios.

Both in the bone-area/body-size comparjsons and in the long-term (replicability) comparisons the question was whether a large number of metacarpals yielded higher or improved values of $r$. Except for technical factors, such as film density, or positioning, mentioned above, the radiographs were not further selected. All of the raw caliper measurements, totaling in excess of 13,500 , were made by one radiogrammetrist (P.S.) throughout, with immediate replicability exceeding 0.98 and long-term replicabilities (for paired radiographs) approximating 0.97 for total subperiosteal area (TA) in both sexes.

In the first step of data analysis we explored the effect of different numbers of metacarpals, from 1 to 6 , on the long-term replicability of various bone areas at midshaft and on percent cortical area (PCA). TA, $\mathrm{MA}$, and CA were considered separately, because total subperiosteal area undergoes minimal dimensional change in adulthood, whereas long-term changes in medullary area and therefore cortical area may be considerable and variable for women aged 40 and beyond.

As shown in Table 1 , and for the 2 entryage groups (30-39 and 40-49), long-term replicability of the 3 bone areas is considerable, especially for total subperiosteal area where it approximates 0.90 overall. Even medullary area shows good long-term replicability over the 21.4 year period, approximating 0.70 overall, despite resorption at the endosteal surface and medullary cavity expansion. However, increasing the number of metacarpals from 1 to 2 to 4 to 6 has very little effect on the long-term replicabilities.

If we pool correlations for TA, MA, and CA to obtain a mean $r$ from the mean $z$ transforms of $r$, we find an overall increase of the order of 0.04 when we compare correlations involving a single metacarpal (II L) and those involving the pair of metacarpals (II L and R). Thereafter, and for a larger number of metacarpals, the net gain in the value of pooled $r$ 's is only 0.02 , through to the maximum number of metacarpals on both hands. While such improvements are statistically significant, given the total subject $\mathrm{N}(376)$ and the relatively high values of $r$, they are not operationally impressive.

When we next consider the correlations between the various bone areas (TA, MA, and $C A I$ and the measures of body size and body composition, we find positive and systematically significant correlations throughout. As shown in Table 2, heavier women and women with a higher FFW and taller women do have larger bone areas but PCA (percent cortical area) is effectively unrelated to weight and fat-free weight, by virtue of its mode of calculation. However, increasing the number of metacarpals from 1 through 6 provides little improvement in the correlations.

Again pooling values of $r$ for TA, MA, and $\mathrm{CA}$, for each combination of metacarpals, there is a slight improvement from II $L$ alone to II $\mathrm{L}$ and $\mathrm{R}$, approximating 0.03 overall. Thereafter the values of $r$ increase but slightly, through a maximum of 6 (i.e., 
TABLE 2. Body size us. bone-area correlations using different numbers of metacarpals

\begin{tabular}{|c|c|c|c|c|c|}
\hline \multirow[b]{2}{*}{ Metacarpal } & \multirow[b]{2}{*}{ Entry Age } & \multicolumn{4}{|c|}{ Bone arca } \\
\hline & & TA & MA & $\mathrm{CA}$ & PCA \\
\hline \multirow{3}{*}{ II L. only } & & ght cor & & & \\
\hline & $30-39$ & 0.162 & -0.001 & 0.191 & 0.038 \\
\hline & $40-49$ & 0.143 & -0.049 & 0.185 & 0.103 \\
\hline \multirow[t]{2}{*}{ II $\mathrm{L}+\mathrm{R}$} & $30-39$ & 0.215 & 0.029 & 0.243 & 0.018 \\
\hline & $40-49$ & 0.125 & 0.024 & 0.138 & 0.019 \\
\hline \multirow{2}{*}{ II-III L + R } & $30-39$ & 0.203 & 0.037 & 0.232 & -0.002 \\
\hline & $40-49$ & 0.121 & 0.002 & 0.146 & 0.032 \\
\hline \multirow[t]{2}{*}{ II-III-IV L $+\mathrm{R}$} & $30-39$ & 0.177 & 0.015 & 0.232 & 0.011 \\
\hline & $40-49$ & 0.132 & -0.014 & 0.155 & 0.025 \\
\hline \multirow{3}{*}{ II L only } & & dy mas & & & \\
\hline & $30-39$ & 0.206 & 0.053 & 0.214 & -0.007 \\
\hline & $40-49$ & 0.178 & -0.062 & 0.231 & 0.117 \\
\hline \multirow[t]{2}{*}{ II $\mathrm{L}, \mathrm{R}$} & $30-39$ & 0.263 & 0.113 & 0.257 & -0.060 \\
\hline & $40-49$ & 0.145 & -0.022 & 0.182 & 0.067 \\
\hline \multirow[t]{2}{*}{ II-III L + R } & $30-39$ & 0.285 & 0.110 & 0.288 & -0.056 \\
\hline & $40-49$ & 0.182 & -0.022 & 0.234 & 0.068 \\
\hline \multirow{2}{*}{ II-III-IV L + R } & $30-39$ & 0.263 & 0.077 & 0.300 & -0.087 \\
\hline & $40-49$ & 0.180 & -0.047 & 0.243 & 0.085 \\
\hline \multirow{3}{*}{ II L only } & & ure cor & & & \\
\hline & $30-39$ & 0.295 & 0.179 & 0.253 & -0.133 \\
\hline & $40-49$ & 0.200 & 0.010 & 0.224 & 0.053 \\
\hline \multirow[t]{2}{*}{ II $L+R$} & $30-39$ & 0.338 & 0.227 & 0.287 & -0.170 \\
\hline & $40-49$ & 0.188 & 0.090 & 0.183 & -0.035 \\
\hline \multirow[t]{2}{*}{ II-III L $+R$} & $30-39$ & 0.380 & 0.253 & 0.315 & -0.193 \\
\hline & $40-49$ & 0.249 & 0.083 & 0.254 & -0.018 \\
\hline \multirow{2}{*}{ II-III-IV I. + R } & $30-39$ & 0.265 & 0.237 & 0.328 & -0.184 \\
\hline & $40-49$ & 0.228 & 0.051 & 0.262 & -0.008 \\
\hline
\end{tabular}

${ }^{1}$ Correlations in excess of +0.13 are significant for the younger women as are correlations in excess of 0.17 for the older women.

Metacarpals II-IV L and R). The improved values of $r$ are not statistically significant, compared with the correlations involving Metacarpal II (L) alone.

These functional comparisons (bone areas vs. body size and bone areas compared over a 21.4 year period) are in accordance with the full cluster of dimensional intercorrelations comparing different numbers and combinations of metacarpals with the sum of 6 . In this separate analysis, the paired second metacarpals do show improved correlations compared with Met II (L) alone but the pairings Met II ( $\mathrm{L}$ or R) and Met III (L or R) are equally predictive. Beyond 2 metacarpals, in any combination, 3,4 , or 5 metacarpals add little improvement.

The 21.4 year replicability studies (Table 1 ), the body-size bone-area studies (Table 2), and the correlational matrix involving all possible combinations of metacarpals are thus in agreement. Metacarpal II (L) alone provides most of the useful information on TA, MA, CA, and PCA but a combination of metacarpals (II L and R) may be slightly more informative.

As shown in this methodological study involving 376 adult women followed for 21.4 years, the historic decision to concentrate on a single metacarpal on one side of the body was completely justified. For descriptive purposes, or for calculating age-associated trends in bone areas, or when investigating bone-size/body-size relationships, the second left metacarpal may be as useful as a combination of metacarpals II-IV on both hands. Though we have here concentrated our analyses to 2 successive age-cohorts and intraindividual correlations, this statement also applies to the analysis of intraindividual bone changes, as we have separately demonstrated (Garn et al., 1991).

When we investigate long-term replicabilities in bone areas (TA, MA, and CA), the relatively high $0.7-0.9$ replicabilities necessarily limit the amount of improvement that can be expected from the use of additional metacarpals. Even for medullary area (MA) which changes much between the fifth and seventh decades, adding metacarpals up to the maximum of 6 adds little to the replicability values. However, 2 metacarpals (II L and $\mathrm{R}$ or II and III L) do increase replicability somewhat. When we compare intraindividual body-size vs. bone-area correlations, which are generally low (circa $0.2-0.25$ ), in- 
creasing the number of metacarpals up to the maximum scarcely justifies the increased measuring time.

Moreover, adding more metacarpals to the bone sample also increases the number of measuring errors, which may then sum or subtract. There are 2 measuring errors when $\mathrm{CA}$ is calculated for any 1 metacarpal since $\mathrm{CA}=\mathrm{TA}-\mathrm{MA}$. Doubling the number of metacarpals doubles the number of possible measuring errors, which increases sixfold for 6 metacarpals and twelvefold when a pair of sequential radiographs is considered. Exactly the same problem obtains with other approaches such as absorptiometry. The summation of measuring errors may explain why correlations involving 6 metacarpals may be lower than correlations involving 2 or 4 .

In any event, this study demonstrates that a single metacarpal (Met II) on one hand may be nearly as representative of bone area (CA) or bone quality (PCA) as a larger number of metacarpals up to a total of 6 . Published age-trends from Yugoslavia (Kusec et al., 1988) and Holland (Van Hemert et al., 1990 ) using 6 metacarpals may therefore be no more informative than analyses using Metacarpal II alone or, possibly, Metacarpal III alone (cf. Horsman, 1976).

\section{ACKNOWLEDGMENTS}

This project has been funded in part with federal funds from the U.S. Department of Agriculture, Agricultural Research Service, under contract $533 \mathrm{~K} 06-5-10$. The contents of this publication do not necessarily reflect the views or policies of the U.S. Department of Agriculture.

We wish to thank Dr. Priya Singh for completion of the radiogrammetric measurements and Audrey Tran for assistance in the bibliographic compilation and manuscript completion.

\section{LITERATURE CITED}

Garn SM (1963) Human biology and research in body composition. Ann. N.Y. Acad. Sci. 110:429-446.

Garn SM (1970) The Earlier Gain and the Later Loss of Cortical Bone. Springfield, IL: Charles C Thomas.

Garn SM, Poznanski AK, and Larson KE (1976) Metacarpal lengths, cortical diameters and areas from the Ten-State Nutrition Survey including: estimated skeletal weights, weight, and stature for Whites, Blacks, and Mexican-Americans. In FG Jaworski (ed.): Proceedings of the First Workshop on Bone Morphometry. University of Ottawa Press, pp. 367-391.

Garn SM, Sullivan TV, and Hawthorne VM (1989) Fatness and obesity of the parents of obese individuals. Am. J. Clin. Nutr. 50:1308-1313.

Garn SM, Sullivan TV, Decker SA, Larkin FA, and Hawthorne VM (1991) Continuing bone expansion and increasing bone loss over a two-decade period in men and women from a total community sample. Am. J. Hum. Biol. 3 (in press).

Horsman A (1976) Bone mass. In BEC Nordin (ed.): Calcium. Phosphate and Magnesium Metabolism. New York: Churchill Livingstone, pp. 357-404.

Kusec V, Simic D, Chaventre A, Tobin JD, Plato CC, and Rudan P (1988) Age, sex and bone measurements of the second, third and fourth metacarpal (Island of Pag, SR Croatia, Yugoslavia). Coll. Antropol. 12:309-322.

Napier JA, Johnson BC, and Epstein FH (1972) The Tecumseh community health study. In II Kessler and ML Levin (eds.): Casebook of Community Studies. Baltimore: Johns Hopkins Press, pp. 15-46.

Van Hemert AM, Vandenbroucke JP, Hofman A, and Valkenburg HA (1990) Metacarpal bone loss in middle-aged women: "Horse racing" in a 9-year population based follow-up study. J. Clin. Epidemiol. 43:579-588. 